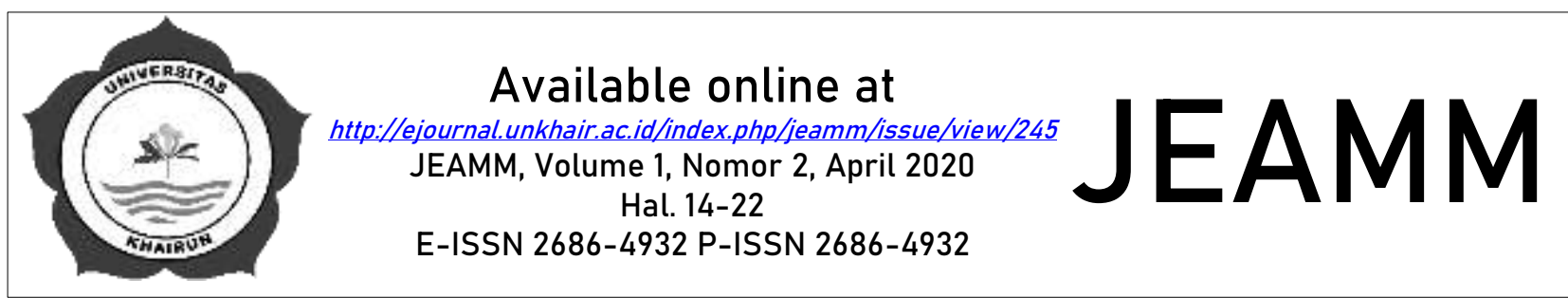

\title{
HUBUNGAN KAPABILITAS INOVASI, BERBAGI PENGETAHUAN, DAN LUARAN PRODUK BARU PADA SEKTOR USAHA INDUSTRI KREATIF
}

\author{
${ }^{1}$ Intan Zoraya, ${ }^{2}$ Akram Harmoni Wiardi, ${ }^{3}$ Sugeng Susetyo \\ Fakultas Ekonomi, Universitas Bengkulu \\ Email: 1intanzoraya86@gmail.com, 2akramharmoniw@gmail.com, \\ 3sugeng@unib.ac.id
}

Dikirim, 3 Maret 2020 Revisi, 10 Maret 2020 Diterima, 23 Maret 2020

\begin{abstract}
ABSTRAK
Penelitian ini bertujuan menguji hubungan berbagi pengetahuan dan kapabilitas inovasi. Pada penelitian ini juga akan dianalisis pengukuran persepsi mengenai kepabilitas inovasi pada sektor industri kreatif. Metode dalam penelitian ini adalah metode survei, sampel penelitian yang menjadi responden dalam penelitian ini adalah karyawan yang bekerja pada industri kerajinan UMKM di Provinsi Bengkulu. Penelitian ini dilakukan pada kelompok industri kreatif yang bergerak dibidang kerajinan yang ada di Provinsi Bengkulu. Dari survei yang dilakukan, diperoleh data dari 112 responden yang merupakan karyawan industri berskala kecil dan menengah yang kemudian dianalisis lebih Pengaruh kapabilitas inovasi terhadap luaran produk baru juga didukung dalam penelitian ini. Inovasi memainkan peran penting dalam kesusksesan sebuah perusahaan di dalam kondisi persaingan yang semakin ketat. Perusahaan yang inovatif akan mampu beradaptasi dan merespon dengan lebih baik terhadap perubahan kondisi pasar. Ditambah lagi karena perusahaan yang berskala kecil dan menengah (UMKM) ini mempunyai karakteristik yang lebih fleksibel yang memungkinkan untuk mengambil keputusan yang lebih cepat dalam menghadapi kondisi pasar yang selalu berubah tersebut.
\end{abstract}

Kata Kunci: Berbagi Pengetahuan, UMKM, Inovasi, Kapabilitas, Usaha

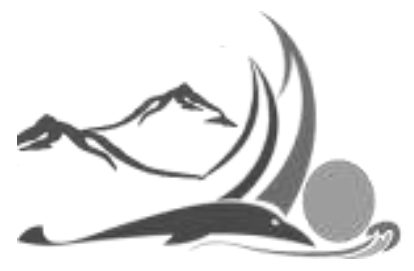

Jurnal Ekonomi, Akuntansi dan Manajemen Multiparadigma Volume 1, Nomor 2, April 2020

\section{ABSTRACT}

The purpose of this research is to examine the relationship of knowledge sharing and innovation capabilities. We operate the measurement of perceptions concerning the reliability of innovation in the creative industry. We operate a survey method, the sample of research respondents in this study are employees who work in the MSME handicraft industry in Bengkulu Province. This research was conducted at a group of creative industries engaged in handicrafts in Bengkulu Province. The Result of the survey collected 112 respondents who are employees of small and medium scale industries. The influence of innovation capabilities on new products development is supported in this research. Innovation capability plays an important role on company's success in an increasingly fierce competition. Innovative companies will be able to adapt and respond better on market conditions. In addition, this small and medium-sized company (MSME) has more flexible characteristics that make it possible to make decisions more quickly in the face of these rapid-changing market conditions.

Keywords: Knowledge, MSME, Innovation, Capability, Business 


\section{PENDAHULUAN}

Pengelolaan industri kreatif seperti UMKM yang memiliki kekuatan finansial, sumberdaya yang memadai, dukungan teknologi, suku bunga yang menarik, dan kualitas pelayanan yang baik dapat menjadi input yang baik dalam peningkatan daya saing. Peluang usaha dan penyaluran dana oleh perbankan dalam bentuk kredit untuk golongan mikro dan menengah merupakan segmen yang diminati oleh industri perbankan saat ini. Bisnis yang mengedepankan dukungan komunitas serta keunggulan tata kelola sumberdaya adalah bisnis yang lebih peka menghadapi kondisi persaingan dalam memenuhi kebutuhan konsumen.

Jantunen, (2005) mengungkapkan bahwa inovasi yang menarik perhatian dan menggugah keterlibatan konsumen cenderung terdapat pada teknologi yang mudah dipahami cara penggunaannya dan efek kegunaan teknologi tersebut. Teknologi merupakan masukan bagi perusahaan untuk meningkatkan strategi bersaing dan berkemampuan melakukan inovasi. Dalam hal ini perusahaan dapat mengembangkan jaringan, memperluas pangsa pasar, memperkenalkan produk terbaru, dan melakukan inovasi, misalnya menggunakan jaringan website atau laman perusahaan untuk meningkatkan layanan secara online dan menjaring komunitas.

Dengan berbagi pengetahuan, perusahaan dapat memperoleh manfaat seperti, peningkatan kinerja perusahaan melalui peningkatan produktivitas, efisiensi, kualitas, dan inovasi (Ismail \& Yusof, 2009). Aktivitas berbagi pengetahuan yang efektif menjadi sumber utama untuk meningkatkan kinerja perusahaan (Kang, Kim, \& Chang, 2008). Dengan melakukan berbagi pengetahuan, suatu perusahaan bisa meningkatkan kreativitas dan keinovasiannya yang bisa menjadi nilai tambah bagi perusahaan.

Menurut Lin, (2007) pengetahuan itu sangat berpengaruh terhadap peningkatan kemampuan inovasi perusahaan, inovasi produk, dan peningkatan kinerja perusahaan. Semakin tinggi tingkat pengetahuan yang dimiliki oleh perusahaan, maka akan semakin tinggi tingkatan inovasi dan kinerja keuangan perusahaan. Hal ini berkaitan dengan penerimaan manfaat teknologi yang dirasakan oleh konsumen perusahaan jasa keuangan. Meskipun demikian, masih perlu diuji secara empiris kekuatan pengaruhnya pada kinerja perusahaan meskipun variabel tingkat inovasi perusahaan dapat dipengaruhi secara positif oleh variabel pengetahuan.

Namun demikian, kebanyakan selama ini penelitian mengenai inovasi hanya berfokus pada proses berbagi pengetahuan untuk mendapatkan sumber daya pengetahuan baru yang bertujuan untuk meningkatkan kemampuan inovasi perusahaan (Liao, 2006; Lin, 2007), karena pada dasarnya aktivitas inovasi itu adalah bagaimana mengimplementasikan pengetahuan, ide, atau aktivitas baru ke dalam perusahaan (Pierce \& Delbecq, 1977). Penelitian yang dilakukan oleh (Miles, 2005) menyatakan bahwa jika perusahaan ingin menjadi inovatif, perusahaan harus berinteraksi dan saling bertukar pengetahuan dan ide dengan pihak lain di lingkungannya. Para pelaku industri kini mulai menyadari bahwa mereka harus lebih mengandalkan sumber daya manusia yang kreatif. Kemudian pada tahun 1990-an era ekonomi baru yang mengintensifkan pemanfaatan informasi dan kreativitas, yang populer disebut ekonomi kreatif yang digerakkan oleh sektor industri yang disebut industri kreatif. Pengertian industri kreatif menurut Kementerian Perdagangan Republik Indonesia adalah industri yang berasal dari pemanfaatan kreativitas, keterampilan serta bakat individu untuk menciptakan kesejahteraan serta lapangan pekerjaan melalui penciptaan dan pemanfaatan daya kreasi dan daya cipta individu tersebut. Berdasarkan penjelasan tersebut peneliti tertarik untuk melakukan analisis hubungan berbagi pengetahuan terhadap kemampuan inovasi pengelola industri kreatif.

Perusahaan yang bisa mengumpulkan dan mengintegrasikan pengetahuan yang unik, jarang, dan sulit untuk direplikasi oleh pesaingnya, memiliki potensi untuk meningkatkan kemampuan inovasinya, sehingga berbagi pengetahuan itu sangat 
berpengaruh terhadap peningkatan kemampuan inovasi perusahaan. Menurut (Lin, 2007), kemampuan perusahaan untuk mentransformasikan dan mengeksploitasi pengetahuan akan sangat menentukan tingkat keinovasian yang dilakukan perusahaan, seperti kemampuan dalam menyelesaikan masalah dan reaksi terhadap informasi baru.

Berbagi pengetahuan sangat diperlukan untuk meningkatkan kemampuan inovasi perusahaan. Pengalaman dan kreativitas yang dimiliki individu dalam sebuah perusahaan perlu untuk disebarkan dan saling diintegrasikan dengan pengetahuan yang dimiliki individu yang lain sehingga perusahaan bisa mengembangkan proses, pelayanan, maupun produk baru. Perusahaan yang mendorong karyawannya untuk berkontribusi dalam berbagi pengetahuan di dalam kelompok atau perusahaan, cenderung akan dapat menghasilkan ideide baru dan mengembangkan peluang bisnis baru melalui sebuah aktivitas inovasi (Darroch \& McNaughton, 2002). Kemampuan perusahaan untuk mendapatkan pengetahuan yang baru sangat diperlukan perusahaan untuk berinovasi karena dengan pengetahuan baru tersebut perusahaan bisa mendapatkan informasi baru yang kemudian bisa diintegrasikan dengan pengetahuan yang ada dan diterapkan ke dalam perusahaan (Liao, 2006). Hasil penelitian Križman, (2009) juga menunjukkan hasil yang positif terhadap pengaruh dari berbagi pengetahuan dengan inovasi yang dilakukan perusahaan. Dengan demikian dapat dikatakan bahwa berbagi pengetahuan menjadi syarat utama dalam berinovasi (Kokacova \& Mala, 2009).

Inovasi mencerminkan kemauan mendasar untuk berangkat dari teknologi yang sudah ada atau praktik dan usaha di luar negeri saat ini. Inovasi mengacu pada kecenderungan industri kreatif memulai dan mendukung ide-ide baru, eksperimen dan proses kreatif yang dapat mengakibatkan produk baru, jasa atau proses teknologi, atau eksploitasi pasar baru. Sedangkan proaktif mengacu pada UKM mengantisipasi dan bertindak atas masa depan keinginan dan kebutuhan di pasar, dalam rangka untuk menciptakan keunggulan penggerak pertama di depan pesaing (Lumpkin \& Dess, 2001).

Hasil penelitian Križman, (2009) juga menunjukkan hasil yang positif terhadap pengaruh dari berbagi pengetahuan dengan inovasi yang dilakukan perusahaan. Dengan demikian dapat dikatakan bahwa berbagi pengetahuan menjadi syarat utama dalam berinovasi (Kokacova \& Mala, 2009). Berdasarkan penelitian tersebut maka pada penelitian ini disusun hipotesis sebagai berikut:

H1: Berbagi pengetahuan berpengaruh positif pada kapabilitas inovasi perusahaan.

H2: Kapabilitas inovasi berpengaruh positif terhadap luaran produk baru pada industri kreatif.

\section{METODE PENELITIAN}

Penelitian ini dilakukan dengan metode survei memanfaatkan kuesioner untuk mendapatkan data secara langsung. Setting penelitian ini dilakukan di Provinsi Bengkulu dengan sampel individu pengelola industri kreatif yang berdomisili di Provinsi Bengkulu. Metode pemilihan sampel dalam riset ini dilakukan secara non-probability dengan teknik purposive sampling. Peneliti membagikan kuesioner kepada responden yang memiliki kriteria yang telah ditentukan, yaitu pengelola industri kreatif yang berlokasi di Provinsi Bengkulu. Jumlah responden dalam penelitian ini sejumlah 112 responden, penentuan jumlah responden berdasarkan ukuran sampel penelitian yang didapatkan dari data statistik dinas perdagangan Provinsi Bengkulu.

Penelitian ini menggunakan uji validitas dengan factor loading $\geq 0,5$ dan reliabilitas dengan Cronbach's alpha $\geq 0,7$. Metode analisis data yang digunakan dalam penelitian ini adalah analisis regresi linier sederhana (Hair, Black, Babin, \& Anderson, 2010; Sudarwo, Anfas, \& Buamonabot, 2019; Arilaha, Fahri, Nurlela, Jabid, \& Buamonabot, 2020). Analisis data dilakukan dengan uji regresi menggunakan software SPSS 20.0 for windows. Pengujian 
regresi linier sederhana terkait goodness-of-fit model dalam penelitian ini, peneliti mengukur tiga elemen yaitu nilai statistik $t$, nilai statistik $F$, serta koefisien determinasinya $R^{2}$.

\section{HASIL PENELITIAN DAN PEMBAHASAN}

Pengumpulan data dalam penelitian ini dilakukan dengan menyebarkan kuesioner secara langsung kepada responden. Proses pengumpulan data dilakukan selama 2 minggu. Kuesioner yang disebarkan adalah sebanyak 150 kuesioner. Dari 150 kuesioner yang disebar, kuesioner yang kembali sebanyak 112 kuesioner. Dengan demikian tingkat respon dalam penelitian ini adalah sebesar $74.7 \%$. Dari 150 kuesioner yang terkumpul terdapat 38 kuesioner yang tidak layak untuk diolah dikarenakan tidak diisi lengkap dan tidak memenuhi kriteria, sehingga tidak lolos kaidah purposive sampling yang ditetapkan untuk penelitian ini, sehingga kuesioner yang digunakan untuk dianalisis dalam penelitian ini berjumlah 112 kuesioner.

Gambaran umum mengenai profil responden dalam penelitian ini dijelaskan dalam tabel 1 Responden dalam penelitian merupakan karyawan dan pemilik industri kerajinan yang ada di Provinsi Bengkulu. Secara umum mayoritas responden adalah wanita yaitu sebesar $80 \%$. Kemudian dari semua industri kerajinan yang menjadi sampel, jenis kerajinan yang paling banyak dikerjakan adalah yang terbuat dari bahan kayu atau serat alam, yaitu sebesar $28.1 \%$ setelah itu diikuti kerajinan kain sebesar $21.9 \%$, hasil industri makanan sebesar $20.5 \%$. Ringkasan karakteristik responden tersebut ditunjukkan pada tabel 1 berikut.

Tabel 1 Karakteristik Responden

\begin{tabular}{lcc}
\hline \multicolumn{1}{c}{ Karakteristik } & Jumlah & Persentase \\
\hline Jenis Kelamin: & & \\
-Pria & 23 & $20 \%$ \\
-Wanita & 89 & $80 \%$ \\
\hline Bentuk Kerajinan: & & \\
-Kain & 32 & $21.9 \%$ \\
-Batu & 27 & $18.5 \%$ \\
-Makanan & 30 & $20.5 \%$ \\
-Kayu/serat alam & 41 & $28.1 \%$ \\
-lainnya & 16 & $11.0 \%$ \\
\hline
\end{tabular}

Sumber: data diolah 2019.

Dalam penelitian ini penulis melakukan face validity dengan mengajukan butir-butir pernyataan yang telah diterjemahkan. Kemudian dilakukan uji validitas dengan analisis faktor dengan menggunakan metode maximum likelihood. Untuk mengukur tingkat keterkaitan (intercorrelation) diantara variabel dan kelayakan terhadap analisis faktor, digunakan nilai factor loading yang $\geq 0,5$ sebagai nilai minimum item pernyataan yang diuji dinyatakan layak. Rule of thumb yang dipakai adalah untuk factor loading 0,5 sudah dapat dikatakan memenuhi standar minimal dengan ukuran sampel minimal sejumlah 100 (Hair et al., 2010). Hasil uji validitas berdasarkan nilai factor loading dapat dilihat pada tabel 2 .

Tabel 2 Nilai Standardize Factor Loading Item Pernyataan

\begin{tabular}{lccc}
\hline Item & $\begin{array}{c}\text { Berbagi } \\
\text { Pengetahuan }\end{array}$ & $\begin{array}{c}\text { Kapabilitas } \\
\text { Inovasi }\end{array}$ & $\begin{array}{c}\text { Produk } \\
\text { baru }\end{array}$ \\
\hline BP4 & $\mathbf{0 . 8 6 5}$ & 0.000 & 0.000 \\
\hline BP3 & $\mathbf{0 . 9 6 3}$ & 0.000 & 0.000 \\
\hline BP2 & $\mathbf{0 . 5 9 0}$ & 0.000 & 0.000 \\
\hline BP1 & $\mathbf{0 . 6 2 6}$ & 0.000 & 0.000 \\
\hline K1 & 0.000 & $\mathbf{0 . 7 2 0}$ & 0.000 \\
\hline
\end{tabular}




\begin{tabular}{lccc}
\hline Item & $\begin{array}{c}\text { Berbagi } \\
\text { Pengetahuan }\end{array}$ & $\begin{array}{c}\text { Kapabilitas } \\
\text { Inovasi }\end{array}$ & $\begin{array}{c}\text { Produk } \\
\text { baru }\end{array}$ \\
\hline $\mathrm{K} 2$ & 0.000 & $\mathbf{0 . 7 2 9}$ & 0.000 \\
\hline $\mathrm{K} 3$ & 0.000 & $\mathbf{0 . 6 2 8}$ & 0.000 \\
\hline $\mathrm{K} 4$ & 0.000 & $\mathbf{0 . 6 1 4}$ & 0.000 \\
\hline $\mathrm{K} 5$ & 0.000 & $\mathbf{0 . 8 5 2}$ & 0.000 \\
\hline $\mathrm{K} 6$ & 0.000 & $\mathbf{0 . 5 5 7}$ & 0.000 \\
\hline $\mathrm{I} 5$ & 0.000 & 0.000 & $\mathbf{0 . 5 8 7}$ \\
\hline $\mathrm{I} 4$ & 0.000 & 0.000 & $\mathbf{0 . 6 3 2}$ \\
\hline $\mathrm{I} 3$ & 0.000 & 0.000 & $\mathbf{0 . 6 5 4}$ \\
\hline $\mathrm{I} 2$ & 0.000 & 0.000 & $\mathbf{0 . 4 9 7}$ \\
\hline $\mathrm{I} 1$ & 0.000 & 0.000 & $\mathbf{0 . 7 6 0}$ \\
\hline
\end{tabular}

Sumber: data diolah 2019.

Dari hasil pengujian dapat dilihat bahwa hampir semua item pernyataan memiliki factor loading yang lebih besar dari 0,6. Namun seperti tampak pada tabel 2, untuk item BP1, 62, dan I2 harus didrop karena factor loading item tersebut di bawah 0,6.

Uji reliabilitas dapat dilakukan untuk pengujian konsistensi alat ukur, pengujian ini berhubungan dengan keakuratan dan ketepatan dari prosedur pengukuran (Hair et al., 2010). Reliabilitas konstruk (construct reliability) dapat diketahui dengan melihat hasil perhitungan koefisien Cronbach's alpha. Tabel 3 menunjukkan bahwa alat ukur yang digunakan dalam penelitian ini adalah reliabel. Hal ini ditunjukkan dengan nilai Cronbach's alpha yang memiliki nilai lebih besar dari 0,7 .

Tabel 3 Hasil Uji Reliabilitas

\begin{tabular}{lcc}
\hline \multicolumn{1}{c}{ Variabel } & $\begin{array}{c}\text { Cronbach's } \\
\text { Alpha }\end{array}$ & Keterangan \\
\hline Berbagi Pengetahuan & 0.835 & reliabel \\
\hline Produk baru & 0.704 & reliabel \\
\hline Kapabltitas Inovasi & 0.856 & reliabel \\
\hline
\end{tabular}

Sumber: data diolah 2019

Uji hipotesis pertama (H1) dilakukan untuk menguji hubungan antar variabel dalam penelitian ini, yaitu variabel berbagi pengetahuan dan kapabilitas inovasi. Pada tabel 4 disajikan hasil uji secara statistik yang menunjukkan bahwa nilai F statistik sebesar 5,940 pada tingkat signifikansi $0.016(\mathrm{p}<0,05)$ hal ini menunjukkan bahwa secara menyeluruh model dalam penelitian ini memiliki goodness of fit (GOF) yang cukup baik. Nilai GOF baik menunjukkan kesesuaian yang cukup baik antara data empiris dalam penelitian ini dengan model yang diprediksi.

Tabel 4 Hasil Uji Regresi Variabel Penelitian

\begin{tabular}{|c|c|c|c|c|c|}
\hline \multicolumn{6}{|c|}{ ANOVAa } \\
\hline Model & $\begin{array}{l}\text { Sum of } \\
\text { Squares }\end{array}$ & $\mathrm{df}$ & Mean Square & $\mathrm{F}$ & Sig. \\
\hline Regression & .488 & 1 & .488 & 5.940 & $.016^{\mathrm{b}}$ \\
\hline Residual & 9.041 & 110 & .082 & & \\
\hline Total & 9.529 & 111 & & & \\
\hline \multicolumn{6}{|c|}{ a. Dependent Variable: RATA2K } \\
\hline \multicolumn{6}{|c|}{ b. Predictors: (Constant), RATA2BP } \\
\hline
\end{tabular}


Pada tabel 5 hasil uji hipotesis penelitian ini dengan cara melihat pengaruh variabel independen pada variabel dependen secara terpisah pada nilai $t$-statistic. Hasil pengujian menunjukkan bahwa terdapat variabel independen Berbagi Pengetahuan (RATA2BP) yang menunjukkan pengaruh signifikansi 0,016 ( $p$ dibawah 0,05 ) terhadap variabel dependen kapabilitas inovasi (RATA2K). Hasil uji ini menunjukkan bahwa variabel berbagi pengetahuan memiliki pengaruh positif $(t=2,437)$ dan signifikan terhadap variabel kapabilitas inovasi.

Tabel 5 Hasil Uji Regresi Variabel Penelitian

\begin{tabular}{|c|c|c|c|c|c|}
\hline \multicolumn{5}{|c|}{ Coefficients $^{a}$} & \\
\hline & & & Standardized & & \\
\hline & Unstandardized & Coefficients & Coefficients & & \\
\hline & B & Std. Error & Beta & & \\
\hline (Constant) & 3.596 & .211 & & 17.015 & .000 \\
\hline RATA2BP & .118 & .049 & .226 & 2.437 & .016 \\
\hline
\end{tabular}

a. Dependent Variable: RATA2K

Sumber: data diolah 2019

Uji hipotesis kedua (H2) dilakukan untuk menguji hubungan antar variabel dalam penelitian ini yaitu kapabilitas inovasi dan luaran produk baru. Hasil uji hipotesis secara statistik dapat dilihat pada tabel 6.

Tabel 6 Hasil Uji Regresi Variabel Penelitian

\begin{tabular}{|c|c|c|c|c|c|c|}
\hline \multicolumn{7}{|c|}{ ANOVA $^{a}$} \\
\hline \multirow[t]{4}{*}{ Model } & & $\begin{array}{l}\text { Sum of } \\
\text { Squares }\end{array}$ & $\mathrm{df}$ & Mean Square & $\mathrm{F}$ & Sig. \\
\hline & Regression & 1.151 & 1 & 1.151 & 4.495 & $.036^{\mathrm{b}}$ \\
\hline & Residual & 28.178 & 110 & .256 & & \\
\hline & Total & 29.329 & 111 & & & \\
\hline \multicolumn{7}{|c|}{ a. Dependent Variable: RATA2PRODUK } \\
\hline \multicolumn{7}{|c|}{ b. Predictors: (Constant), RATA2K } \\
\hline
\end{tabular}

Pada tabel 6 disajikan hasil uji secara statistik yang menunjukkan bahwa nilai $\mathrm{F}$ statistik sebesar 4,495 pada tingkat signifikansi $0.036(\mathrm{p}<0,05)$ hal ini menunjukkan bahwa secara menyeluruh model dalam penelitian ini memiliki goodness of fit (GOF) yang cukup baik. Nilai GOF baik menunjukkan kesesuaian yang cukup baik antara data empiris dalam penelitian ini dengan model yang diprediksi.

Pada tabel 7 hasil uji hipotesis penelitian ini dengan cara melihat pengaruh variabel independen pada variabel dependen secara terpisah pada nilai $t$-statistic. Hasil pengujian menunjukkan bahwa terdapat variabel independen kapabilitas inovasi (RATA2K) yang menunjukkan pengaruh signifikansi 0,036 ( $\mathrm{p}$ dibawah 0,05 ) terhadap variabel dependen luaran produk baru (RATA2PRODUK). Hasil uji ini menunjukkan bahwa variabel kapabilitas inovasi memiliki pengaruh positif $(\mathrm{t}=2,120)$ dan signifikan terhadap variabel luaran produk baru.

Pengujian dalam hipotesis 1 dilakukan untuk menguji pengaruh berbagi pengetahuan terhadap kapabilitas inovasi. Hasil tersebut menunjukkan bahwa hipotesis 1 didukung pada tingkat signifikansi 0.05 (5\%), sehingga dapat disimpulkan bahwa berbagi pengetahuan berpengaruh positif terhadap kapabilitas inovasi atau dengan kata lain semakin tinggi aktivitas berbagi pengetahuan antar pegawai maka kapabilitas inovasi juga akan meningkat. 
Tabel 7 Hasil Uji Regresi Variabel Penelitian

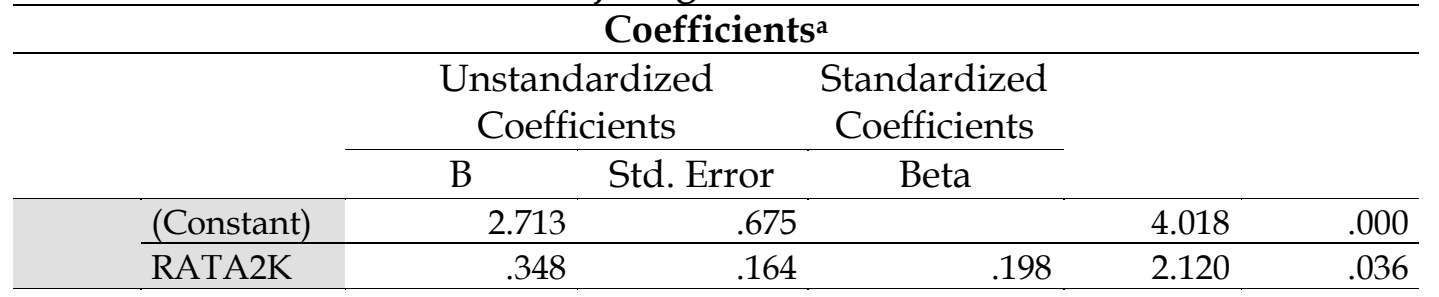

a. Dependent Variable: RATA2PRODUK

Sumber: data diolah 2019

Pengujian dalam hipotesis 2 dilakukan untuk menguji pengaruh kapabilitas inovasi pada luaran produk baru. Hasil tersebut menunjukkan bahwa hipotesis 2 didukung pada tingkat signifikansi 0.05 , sehingga dapat disimpulkan bahwa kapabilitas inovasi berpengaruh terhadap luaran produk baru.

Pentingnya berbagi pengetahuan bagi perusahaan karena bahwa berbagi pengetahuan dapat mengembangkan kemampuan, kompetensi, dan meningkatkan nilai-nilai perusahaan sehingga pada akhirnya memberikan pengaruh yang positif terhadap kinerja perusahaan. Hal tersebut juga didukung oleh studi yang dilakukan oleh Wijk, Jansen, \& Lyles, (2017) dan Weber \& Weber, (2010) yang juga menyatakan bahwa adanya pengaruh positif dari berbagi pengetahuan terhadap kinerja perusahaan. Berbagi pengetahuan akan memberikan pengaruh yang positif terhadap kemampuan inovasi suatu perusahaan. Hal tersebut sesuai dengan hasil penelitian yang dilakukan oleh Lin, (2007). Perusahaan yang bisa mengumpulkan dan mengintegrasikan pengetahuan yang unik, jarang, dan sulit untuk direplikasi oleh rivalnya, memiliki potensi untuk meningkatkan kemampuan inovasinya. Berbagi pengetahuan yang diindikasikan dengan adanya suatu proses saling memberikan pengetahuan, pengalaman, informasi, maupun keterampilan yang dimiliki, juga telah terbukti mempunyai pengaruh yang positif dan signifikan terhadap kapabilitas atau kemampuan perusahaan dalam melakukan inovasi produk, proses, teknik administrasi, dan pelayanannya (Liao, 2006).

Dalam penelitian ini hal tersebut terbukti memberikan hasil yang signifikan dari pengaruh berbagi pengetahuan terhadap kapabilitas inovasi pengrajin. Hal ini berarti bahwa meskipun individu-individu dalam suatu perusahaan mau untuk saling berbagi pengetahuan kepada perusahaannya, dalam hal ini bisa kepada atasannya dan sesama rekan kerjanya, maka pengetahuan tersebut bisa bermanfaat bagi perusahaan untuk digunakan sebagai ideide baru untuk melakukan inovasi. Seperti yang kita ketahui bahwa yang menjadi objek dalam penelitian ini adalah perusahaan yang berskala kecil dan menengah (UKM). Karakteristik dari UKM itu sendiri bisa mempengaruhi aktivitas pengelolaan pengetahuan, mulai dari proses akuisisi pengetahuan, berbagi pengetahuan, hingga penerapan pengetahuan tersebut ke dalam perusahaan (Supyuenyong, Islam, \& Kulkarni, 2009). Menurut (Supyuenyong et al., 2009), UKM memiliki beberapa karakteristik, yaitu terbatasnya jumlah tenaga kerja ahli dan profesional yang dimiliki, jumlah tenaga kerja yang lebih sedikit dan terjadi tingkat perputaran tenaga kerja yang lebih tinggi, serta UKM cenderung lebih fokus pada kegiatan operasional sehari-hari dari pada hal-hal yang bersifat strategik. Oleh karena itu, ketika proses berbagi pengetahuan itu terjadi, proses tersebut tidak berlangsung dengan baik. Karena sedikitnya jumlah tenaga kerja ahli dan profesional yang dimiliki, maka ketersediaan pengetahuan yang berkualitas menjadi lebih sedikit (McAdam \& Reid, 2001) dan proses berbagi pengetahuan yang terjadi cenderung lebih banyak pada pengetahuan yang bersifat tacit (Supyuenyong et al., 2009). Tingkat perputaran tenaga kerja yang tinggi serta umumnya pengetahuan yang dibagi hanya bersifat pengetahuan tacit yang tidak terdokumentasikan dengan baik, sehingga menyebabkan pengetahuan menjadi tidak tersedia setiap saat. 
Kemampuan inovasi suatu organisasi bisa memberikan pengaruh yang positif terhadap kinerja perusahaan. Inovasi dianggap sebagai prediktor yang kuat bagi kinerja perusahaan. Inovasi memang sangat diperlukan bagi perusahaan agar tetap bisa bertahan dari perubahan kondisi pasar. Artz, Norman, Hatfield, \& Cardinal, (2010) juga menyatakan bahwa perusahaan yang berinovasi dengan memperkenalkan produk-produk baru ke pasar akan mendapatkan keuntungan yang lebih baik.

Pengaruh kapabilitas inovasi terhadap luaran produk baru juga didukung dalam penelitian ini. Inovasi memainkan peran penting dalam kesuksesan sebuah perusahaan di dalam kondisi persaingan yang semakin ketat. Perusahaan yang inovatif akan mampu beradaptasi dan merespon dengan lebih baik terhadap perubahan kondisi pasar. Ditambah lagi karena perusahaan yang berskala kecil dan menengah (UKM) ini mempunyai karakteristik yang lebih fleksibel yang memungkinkan untuk mengambil keputusan yang lebih cepat dalam menghadapi kondisi pasar yang selalu berubah tersebut.

\section{SIMPULAN}

Penelitian ini bertujuan untuk menjelaskan pengaruh berbagi pengetahuan dan kemampuan berinovasi terhadap kinerja karyawan pada kelompok industri kreatif yang ada di Provinsi Bengkulu. Dari hasil penelitian yang dilakukan dapat disimpulkan bahwa pertama, berbagi pengetahuan secara signifikan berpengaruh positif terhadap kapabilitas inovasi. Kapabilitas inovasi berpengaruh positif terhadap luaran produk baru. Kedua, kapabilitas inovasi berpengaruh secara signifikan terhadap kemampuan menghasilkan produk baru. Untuk mampu bertahan dan berkembang dalam lingkungan yang tak terduga dan bergejolak, hal-hal baru harus dilakukan atau cara-cara baru harus diadopsi dalam proses bisnis perusahaan. Kreatifitas dari individu-individu dalam perusahaan dalam mengembangkan suatu desain produk baru, proses produksi yang lebih efisien dan efektif maupun pelayanan yang lebih baik kepada pelanggan bisa memberikan dorongan bagi peningkatan keuntungan dan pertumbuhan penjualan perusahaan untuk kesuksesan jangka panjang perusahaan.

Penelitian selanjutnya hendaknya lebih memperhatikan faktor-faktor yang mempengaruhi normalitas data agar asumsi normalitas dapat terpenuhi. Kedua, pengukuran kinerja perusahaan dilakukan tidak hanya secara subjektif tetapi juga dengan melihat kinerja secara objektif dari data-data pada laporan keuangan. Ketiga, menghindari penggunaan satu sumber (single source) untuk unit analisis organisasi. Penelitian selanjutnya diharapkan menggunakan responden dari beberapa industri yang berbeda. Klasifikasi yang telah ditetapkan oleh Kementerian Perdagangan RI mengenai industri yang termasuk dalam kelompok industri kreatif yang lain, seperti periklanan, arsitektur, pasar barang seni, desain, fesyen, video, film dan fotografi, permainan interaktif, musik, seni pertunjukan, penerbitan dan percetakan, layanan komputer dan piranti lunak, televisi dan radio, riset dan pengembangan, bisa menjadi pertimbangan peneliti selanjutnya.

\section{DAFTAR PUSTAKA}

Arilaha, M. A., Fahri, J., Nurlela, Jabid, A. W., \& Buamonabot, I. (2020). Motivation, Physical Work Environment, Non-Physical Work Environment, and Work Satisfaction (Study on the Government of Ternate City ). 194(FANRes 2019), 419-423. https://doi.org/https://doi.org/10.2991/aer.k.200325.084

Artz, K. W., Norman, P. M., Hatfield, D. E., \& Cardinal, L. B. (2010). A Longitudinal Study of the Impact of R\&D, Patents, and Product Innovation on Firm Performance. Journal of Product Innovation Management, 27, 725-740. https://doi.org/doi:10.1111/j.15405885.2010.00747.x

Darroch, J., \& McNaughton, R. (2002). “Examining the Link Between Knowledge Management Practices and Types of Innovation," 3, no. 3 (2002), pp. 210-222. Journal of 
Intellectual Capital, 3(3), 210-222. https:/ / doi.org/doi: 10.1108/14691930210435570

Hair, J., Black, W., Babin, B., \& Anderson, R. (2010). Multivariate Data Analysis: A Global Perspective. In P. P. Hall (Ed.), Multivariate Data Analysis: A Global Perspective (7th Ed., Vol. 7th). Pearson.

Ismail, M. B., \& Yusof, Z. M. (2009). The Relationship Between Knowledge Sharing, Employee Performance and Service Delivery in Public Sector Organisation: A Theoritical Framework. Public Sector ICT Management Review, 3(1), 37-45.

Jantunen, A. (2005). Knowledge-processing capabilities and innovative performance: an empirical study. European Journal of Innovation Management, 8(3), 336-349. https://doi.org/10.1108/14601060510610199

Kang, Y. J., Kim, S.-E., \& Chang, G. W. (2008). The impact of knowledge sharing on work performance: An empirical analysis of the public employees' perceptions in South KoreaNo Title. International Journal of Public Administration, 31(14), 1548-1568. https://doi.org/https:/ / doi.org/10.1080/01900690802243607

Kokacova, D., \& Mala, D. (2009). Knowledge Sharing - The Main Prerequisite of Innovation. Organizaciju Vadyba, 51, 47-56. https://doi.org/https://hdl.handle.net/20.500.12259/36455

Križman, A. (2009). Involvement, Knowledge Sharing and Proactive Improvement as Antecedent of Logistics Outsourcing Performance. 11(3), 233-256.

Liao, L.-F. (2006). A learning organization perspective on knowledge-sharing behavior and firm innovation. Human Systems Management, 25(4), 227-236.

Lin, H. (2007). Knowledge sharing and firm innovation capability : an empirical study. International Journal of Manpower, 28(3), 315-332. https://doi.org/10.1108/01437720710755272

Lumpkin, G. T., \& Dess, G. G. (2001). Linking two dimensions of entrepreneurial orientation to firm performance: The moderating role of environment and industry life cycle. Journal of Business Venturing, 16(5), 429-451. https://doi.org/https://doi.org/10.1016/S0883-9026(00)00048-3

McAdam, R., \& Reid, R. (2001). SME and large organisation perceptions of knowledge management: comparisons and contrasts. Journal of Knowledge Management, 5(3), 231241. https://doi.org/SME and large organisation perceptions of knowledge management: comparisons and contrasts

Miles, I. (2005). Innovation in services. In: The Oxford Handbook of Innovation, J Fagerberg' (DC Mowery). Oxford: Oxford University Press.

Pierce, J. L., \& Delbecq, A. L. (1977). No Title. Academy of Management Review, 2(1), 27-37. https://doi.org/https://doi.org/10.5465/amr.1977.4409154

Sudarwo, R., Anfas, \& Buamonabot, I. (2019). Antecedents of satisfaction choosing higher education: An empirical evidence at the universitas terbuka. International Journal of Scientific and Technology Research, 8(10), 1601-1604.

Supyuenyong, V., Islam, N., \& Kulkarni, U. (2009). Influence of SME characteristics on knowledge management processes: The case study of enterprise resource planning service providers. Journal of Enterprise Information Management, 22(1-2), 63-80. https://doi.org/https://doi.org/10.1108/17410390910922831

Weber, C., \& Weber, B. (2010). Social Capital and Knowledge Relatedness as Promoters of Organizational Performance. International Studies of Management E Organization, 40(3), 23-49. https:// doi.org/10.2753/IMO0020-8825400302

Wijk, R. Van, Jansen, J., \& Lyles, M. (2017). Social Capital, Knowledge Transfer and Performance: Meta-Analitic Evidence. Academy of Management Annual Meeting, 1-6. https://doi.org/https://doi.org/10.5465/ambpp.2008.33663961 